\title{
Selection and validation of a set of reliable reference genes for quantitative RT-PCR studies in the brain of the Cephalopod Mollusc Octopus vulgaris
}

\author{
Maria Sirakov ${ }^{\dagger 1,5}$, Ilaria Zarrella ${ }^{\dagger 1}$, Marco Borra $^{2}$, Francesca Rizzo $^{3}$, \\ Elio Biffali ${ }^{2}$, Maria Ina Arnone ${ }^{3}$ and Graziano Fiorito*1,4
}

Address: ${ }^{1}$ Laboratorio di Neurobiologia, Stazione Zoologica Anton Dohrn, Villa Comunale, 80121 Napoli, Italy, ${ }^{2}$ Molecular Biology Core Service, Stazione Zoologica Anton Dohrn, Villa Comunale, 80121 Napoli, Italy, ${ }^{3}$ Cellular and Developmental Biology, Stazione Zoologica Anton Dohrn, Villa Comunale, 80121 Napoli, Italy, ${ }^{4}$ Functional and Evolutionary Ecology, Stazione Zoologica Anton Dohrn, Villa Comunale, 80121 Napoli, Italy and ${ }^{5}$ Ecole Normale Supérieure de Lyon, Institute of Functional Genomics of Lyon 69964 Lyon, Cedex 07, France

Email: Maria Sirakov - maria.sirakov@ens-lyon.fr; Ilaria Zarrella - zarrella@szn.it; Marco Borra - borra@szn.it; Francesca Rizzo - rizzo@szn.it; Elio Biffali - elio@szn.it; Maria Ina Arnone-miarnone@szn.it; Graziano Fiorito* - gfiorito@szn.it

* Corresponding author †Equal contributors

Published: 14 July 2009

BMC Molecular Biology 2009, 10:70 doi:10.1 186/1471-2199-10-70

This article is available from: http://www.biomedcentral.com/I47I-2199//0/70

(C) 2009 Sirakov et al; licensee BioMed Central Ltd.

This is an Open Access article distributed under the terms of the Creative Commons Attribution License (http://creativecommons.org/licenses/by/2.0), which permits unrestricted use, distribution, and reproduction in any medium, provided the original work is properly cited.

\begin{abstract}
Background: Quantitative real-time polymerase chain reaction (RT-qPCR) is valuable for studying the molecular events underlying physiological and behavioral phenomena. Normalization of real-time PCR data is critical for a reliable mRNA quantification. Here we identify reference genes to be utilized in RT-qPCR experiments to normalize and monitor the expression of target genes in the brain of the cephalopod mollusc Octopus vulgaris, an invertebrate. Such an approach is novel for this taxon and of advantage in future experiments given the complexity of the behavioral repertoire of this species when compared with its relatively simple neural organization.
\end{abstract}

Results: We chose $16 \mathrm{~S}$, and I8S rRNA, actB, EEFIA, tubA and ubi as candidate reference genes (housekeeping genes, HKG). The expression of $16 \mathrm{~S}$ and $18 \mathrm{~S}$ was highly variable and did not meet the requirements of candidate HKG. The expression of the other genes was almost stable and uniform among samples. We analyzed the expression of HKG into two different set of animals using tissues taken from the central nervous system (brain parts) and mantle (here considered as control tissue) by BestKeeper, geNorm and NormFinder. We found that HKG expressions differed considerably with respect to brain area and octopus samples in an HKG-specific manner. However, when the mantle is treated as control tissue and the entire central nervous system is considered, NormFinder revealed tubA and ubi as the most suitable HKG pair. These two genes were utilized to evaluate the relative expression of the genes FoxP, creb, dat and $T H$ in $O$. vulgaris.

Conclusion: We analyzed the expression profiles of some genes here identified for $O$. vulgaris by applying RT-qPCR analysis for the first time in cephalopods. We validated candidate reference genes and found the expression of $u b i$ and tubA to be the most appropriate to evaluate the expression of target genes in the brain of different octopuses. Our results also underline the importance of choosing a proper normalization strategy when analyzing gene expression by QPCR taking into appropriate account the experimental setting and variability of the sample of animals (and tissues), thus providing a set of HGK which expression appears to be unaffected by the experimental factor(s). 


\section{Background}

Relative quantification of mRNA transcripts requires endogenous normalizers, i.e. reference genes. The normalization of the expression of target genes favors the elimination of unspecific variation caused by differences in starting material, RNA extraction, enzymatic efficiencies, transcriptional activity and presence of inhibitors in the samples. A suitable reference gene has to $i$. be adequately expressed in the tissue of interest, ii. not be co-regulated, and iii. show comparable expression levels with target genes. In addition, it should show reduced variability in expression levels among samples and experimental conditions [1-4].

A brief review of the literature shows that a limited number of genes is commonly utilized in RT-qPCR experiments as reference. However, strategies have been developed to validate the use of reference genes experimentally [2,4-10] and to apply computational approaches that allow to monitor the stability of genes in respect to others in all samples $[11,12]$, thus allowing proper normalization of RT-qPCR data.

The aim of the present study is to identify candidate genes in the cephalopod mollusc Octopus vulgaris that could be used in RT-qPCR experiments as internal reference (housekeeping genes, HKGs) to normalize the expression of target genes. Such an approach is novel for this taxon and may result of great advantage in future experiments given the complexity of the behavioral repertoire of this animal when compared with its relatively simple neural organization $[13,14]$.

\section{Results}

The brain (supra- and sub-oesophageal masses and optic lobes [15]) and, as control tissue, the mantle of naïve $O$. vulgaris were utilized as samples in this study. Two different sets of individuals were used: a broad collection (for both size and age) caught throughout the year (set a) and a restricted sample (in body size) collected exclusively during the summer (set b).

\section{Expression stability of candidate reference genes} Likewise other studies, we chose 16S rRNA (encoded in the mitochondrial DNA), $\beta$-actin ( $a c t B)$, elongation factor $1 \mathrm{~A}(E E F 1 A)$ and $\alpha$-tubulin $(t u b A)$ as candidate reference genes (sequences available in Gene Bank, Table 1). In addition, partial sequences of $18 \mathrm{~S}$ rRNA and ubiquitin (ubi) were also identified for this work (see Table 1).

The range of cycle thresholds for the HKG analyzed (Figure 1) resulted quite different among samples. It is noteworthy to report that $16 \mathrm{~S}$ rRNA exhibited the highest range of variation in $\mathrm{Ct}$ (note the larger interquartile range in Figure 1), when compared with the other genes, in all tissues considered ( cytoskeleton structural gene, the expression of $a c t B$ was higher in the mantle than in the brain (set a and b) also when compared with the other candidate reference genes (Figure 1; but note also 18S).

The gene expression stability of the candidate reference genes for our two octopus samples sets was evaluated with BestKeeper [16], geNorm [12] and NormFinder [17]. A tabularized overview of the results is presented in Figure 2. A stepwise elimination of reference genes according to the results obtained from each analysis provided differences and commonalities in the results of the application for the three algorithms. Interestingly, a different result was obtained for each set of samples (set a vs set b) and when the different tissues were considered (Figure 2). When analyzing all tissue samples together for animals belonging to set a (highlighted row), Bestkeeper and NormFinder revealed $u b i$ as the best candidate. GeNorm suggested the pair tubA-ubi to be the best combination of two genes, but with $M$ values above the recommended threshold. In addition, the expression of $t u b A$ was considered too variable for Bestkeeper.

The analysis of samples taken from a more homogeneous set of animals (set b, highlighted row) provided, as expected, a consensus between the three algorithms. In fact, each software indicated the pair $t u b A-u b i$ as the best combination of reference genes ( $u b i$ is the best gene according to NormFinder).

A different pattern appeared when both sets of samples were considered (Figure 2). Again, geNorm was not capable to provide a combination of reference genes because the variability in expression resulted in $M$ values above the suggested level of acceptance. Similarly, BestKeeper indicated $t u b A$ as the best reference gene, but suggested that the levels of $u b i$ mRNA in the different samples were too variable to be recommended as reference. NormFinder found $u b i$ as the best HKG.

NormFinder also allows to define experimental conditions/samples in a data set [17]. For our purposes, here we considered the mantle as control tissue when studying the expression of different genes in the brain. In these circumstances, NormFinder revealed $u b i$ and $t u b A$ as the best combination of reference genes for evaluating the expression of target genes in animals belonging to different sets.

\section{Expression level of target genes}

In order to apply this pair of reference genes ( $t u b A-u b i)$, we analyzed the relative expression of target genes in the two sets of animals in different tissues (Figure 3). The two transcription factors considered in this study [Forkhead box-P (FoxP): set a; c-AMP response element binding $(\mathrm{creb})$ : set b] did not have significantly different levels of expression in different tissues, similar to what resulted by 
Table I: Gene products, accession number (AN) and gene ontology accession number (GO) of genes considered in this work.

\begin{tabular}{|c|c|c|c|c|c|c|}
\hline Gene product & AN & $\mathbf{G O}^{\mathbf{a}}$ & $\mathbf{P}$ & Primer sequence 5' - 3' & AS & $\mathbf{E}^{\mathbf{b}}$ \\
\hline \multirow[t]{2}{*}{$\alpha$-tubulin } & $\underline{X 15845}$ & 0005874 & $\mathrm{~F}$ & ACTGGTGTCCAACTGGCTTC & 105 & 2.00 \\
\hline & & & $R$ & TGCTTAACATGCACACAGCA & & \\
\hline \multirow[t]{4}{*}{$\beta$-actin } & $\mathrm{AB} 053937$ & 0005200 & $\mathrm{FI}$ & TGATGGCCAAGTTATCACCA & 103 & 1.90 \\
\hline & & & RI & TGGTCTCATGGATACCAGCA & & \\
\hline & & & $\mathrm{F} 2$ & TCCAGGCTGTGTTGTCTCTG & 148 & 1.80 \\
\hline & & & $\mathrm{R} 2$ & AGATCACGACCAGCCAAGTC & & \\
\hline \multirow[t]{2}{*}{ CREB } & F]617443* & 0003700 & $\mathrm{~F}$ & ACAGTATGCCCAAGGTCCTG & 122 & 1.80 \\
\hline & & & $\mathrm{R}$ & TTCCAGTGGTTGCCATAACA & & \\
\hline \multirow[t]{2}{*}{ Dopamine transporter } & F]61744I* & 0005329 & $\mathrm{~F}$ & GCCCTAGACGGCATCAAATA & 109 & 2.00 \\
\hline & & & $\mathrm{R}$ & ATCCTGGTCCAAGGGAAAAG & & \\
\hline \multirow[t]{2}{*}{ Elongation factor } & AY651883 & $00064 \mid 4$ & $\mathrm{~F}$ & ACGAAGGCTGGGAAATTGA & 104 & 2.00 \\
\hline & & & $\mathrm{R}$ & TGGTCTCTCCGTTGGTCTCT & & \\
\hline \multirow[t]{2}{*}{ Forkhead box protein $\mathbf{P}$} & Fj617444* & 0003700 & $\mathrm{~F}$ & TCCACACCTGCCATGAGTT & 149 & 2.00 \\
\hline & & & $\mathrm{R}$ & GATTGGTCCCACACTGCTG & & \\
\hline \multirow[t]{2}{*}{ Tyrosine hydroxylase } & Fj617442* & 0018336 & $\mathrm{~F}$ & CTCATTGCAGACATGGCATT & 128 & 1.70 \\
\hline & & & $\mathrm{R}$ & GCGTGAGTCGGAAACAGATT & & \\
\hline \multirow[t]{2}{*}{ Ubiquitin/ribosomal protein S27a } & F]617440* & 0016567 & $\mathrm{~F}$ & TCAAAACCGCCAACTTAACC & 113 & 1.90 \\
\hline & & & $\mathrm{R}$ & CCTTCATTTGGTCCTTCGTC & & \\
\hline \multirow[t]{2}{*}{$16 S$} & A] 616309 & 0005200 & $\mathrm{~F}$ & TTGGGGCTAGAATGAATGGT & 112 & 1.90 \\
\hline & & & $\mathrm{R}$ & GGTCTTTTCGTCCCTTTAAACA & & \\
\hline \multirow[t]{2}{*}{$18 S$} & F]617439* & 0005200 & $\mathrm{~F}$ & AGTTCCGACCGTAAACGATG & 142 & 1.80 \\
\hline & & & $\mathrm{R}$ & CCCTTCCGTCAATTCCTTTA & & \\
\hline
\end{tabular}

Primer sequences (F: forward; R: reverse), amplicon size in bp (AS) and calculated reaction efficiencies (E) for RT-qPCR experiments are also reported. Newly identified genes in $O$. vulgaris are marked by an asterisk.

a. According to Gene Ontology (http://www.geneontology.org/, last visited Aug, 2008) for each gene is listed a GO accession number.

b. Efficiency for each primer pair was derived from standard curves using five serial dilutions of cDNA samples, as described in Methods.

analyzing the expression profile of dopamine transporter (dat, set $\mathrm{b})$ in the octopuses ( $\mathrm{P}>0.05$ for all comparisons). On the contrary, tyrosine hydroxylase $(\mathrm{TH}$, set b) mRNAs reached expression levels in the optic lobes that were significantly higher when compared with those observed in other tissues $(\mathrm{P}<0.05$; Figure 3$)$.

\section{Discussion and conclusion}

In this study, we analyzed the expression profiles of some genes here identified for Octopus vulgaris for the first time. We applied RT-qPCR analysis, which is unprecedented in cephalopods, and, as a prerequisite, we also validated candidate reference genes. Normalization strategies are required to correct sample-to-sample variability in order to reveal gene-specific variation among experimental conditions and/or tissues. Similarly to what occurs in other animal models [e.g. $[18,19]]$, normalization of mRNA levels to the cell number is not possible for $O$. vulgaris tissues.
Our experiments showed that the expression of several so called housekeeping genes vary among different conditions (possibly body size or seasonality) and/or tissues (i.e. mantle vs brain), but also when the different parts in the brain of the octopus (masses) are considered. However, in such circumstances an algorithm that takes into account different conditions in a given experimental design (NormFinder [17]) results to be beneficial for the identification of suitable reference genes to be used in RTqPCR experiments. This was our case. NormFinder allowed us to identify $u b i$ and $t u b A$ as the appropriate reference genes for most of the analyzed samples. Moreover, this gene pair resulted to be chosen as the best combination when a tissue (mantle in our condition) is used as control to study the expression of different genes in the brain. We applied this reference gene pair to analyze the level of expression of our target genes (creb, dat, TH, FoxP) in different regions of Octopus brain applying a geometric 


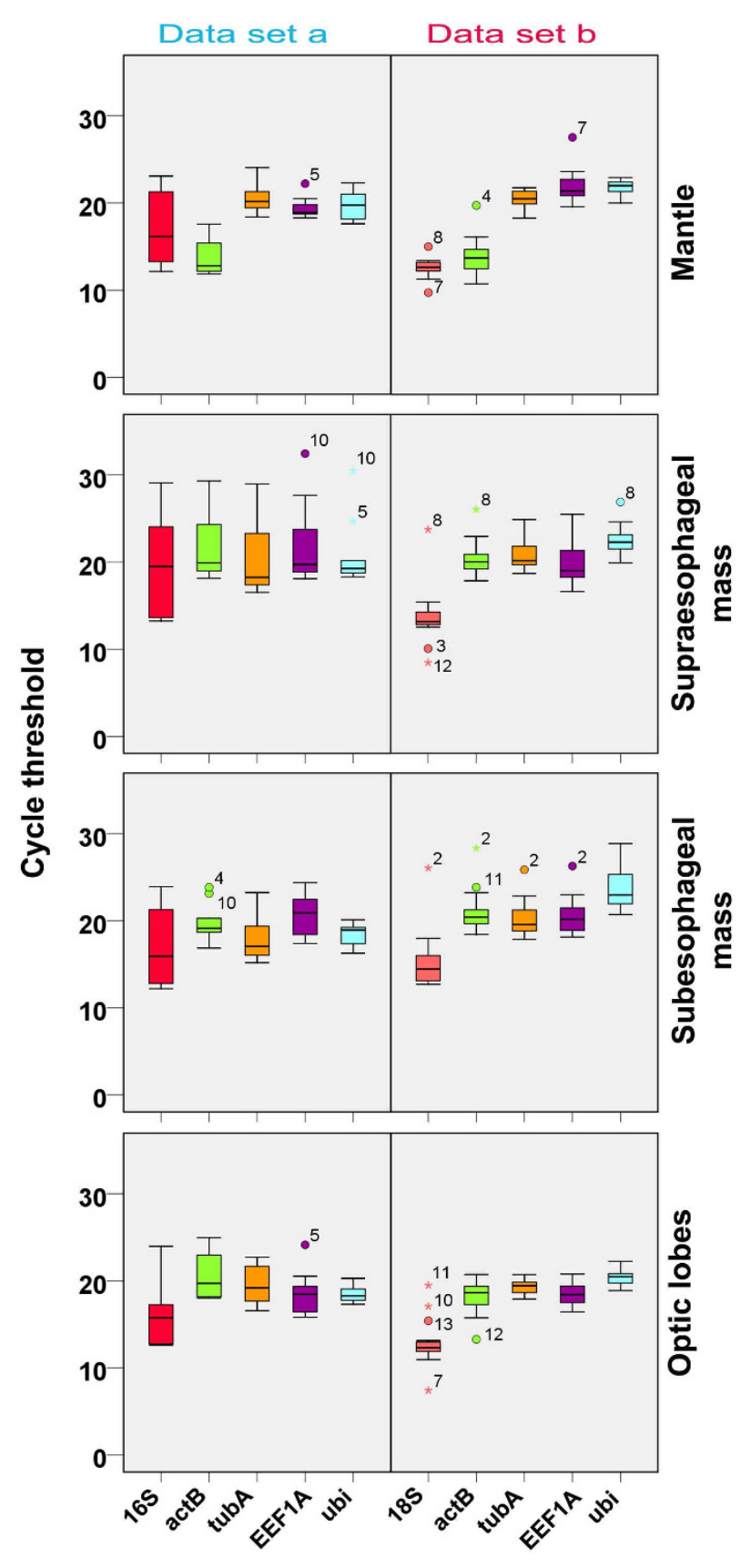

\section{Figure I}

RT-qPCR cycle threshold (Ct) values of candidate reference genes among different tissues in two data sets. Cycle threshold distribution values $(C t)$ of $16 \mathrm{~S}$, act $B$, tubA, EEFIA and ubi (set a, left panel) and I8S, actB, tubA, $E E F I A$, ubi (set b, right panel) from mantle, supraoesophageal and suboesophageal masses and optic lobes of $O$. vulgaris. The distribution is shown by vertical box plot as medians (lines), interquartile range (boxes) and ranges (whiskers). Circles mark outliers with values between I.5 and 3 times the interquartile range; asterisks mark outliers having $\mathrm{Ct}$ more than three times the interquartile. approach that take into account primer efficiencies for both reference and target genes.

In our experimental conditions, $16 S$ and $18 S$ rRNAs, EEF1A and $a c t B$ resulted not reliable as reference genes in terms of stability and relative levels of expression, in analogy to what is reported for other species [e.g. $[6,9,10,20]]$.

In particular, the expression of $16 S$ rRNA allowed to identify two discrete groups of animals (60-fold differences in $\mathrm{Ct}$; data not shown) in our sample. This did not correlate with sex, seasonality or the body size of the animals and was independent from the tissues considered. The fact that $16 S$ rRNA is a mitochondrial gene suggests that this may be related with physiological (and/or metabolic) status of the animals. Similarly, we cannot exclude that $18 \mathrm{~S}$ rRNA expression may be influenced by physiological conditions. Moreover, we found that $a c t B$ reached higher levels of expression in the mantle when compared to the brain; it also resulted expressed with high interquartile ranges among samples, similarly to what resulted in other experimental settings [21]. Surprisingly, the three algorithms did not indicate EEF1A as a suitable reference gene in our experimental conditions (except for Bestkeeper: mantle set a and SUB set b). However, its expression is comparable to the other putative reference genes (Figure 1 ). This resembles what recently found in other systems [22].

In order to account for the largest inter-individual variability in the octopus, we analyzed some target genes separately in two different groups of animals, one representing the whole population (set a) and one more restricted to sub-adults of the summer season (set b). The expression levels detected for each animal group suggest a correlation between data set heterogeneity and gene expression variability as deduced by the elevated $\mathrm{Ct}$ value variability obtained from samples belonging to octopuses of set a.

Moreover, octopuses of our samples showed low expression levels for transcription factors when compared with mRNA coding for proteins highly utilized in the metabolic pathway (i.e. FoxP and creb vs dat and $T H$; data not shown). It is interesting to note that dopamine-related genes were abundantly expressed in the optic lobes of $O$. vulgaris, confirming previously published data [review in [23]].

In conclusion, we were able to identify reference genes to be utilized for normalization in particular conditions in RT-qPCR experiments designed to test gene expression in different tissues of $O$. vulgaris and to describe inter-individual variability in gene expression in naïve octopuses. 


\begin{tabular}{|c|c|c|c|c|c|c|c|c|c|c|c|c|c|c|c|c|c|c|c|c|c|c|c|c|c|c|c|c|c|}
\hline & & & amp & & & & Bestk & keepe & & & & & geN & Norm & & & & Nort & mFind & $\operatorname{der}(b$ & best) & & & Nor & mFin & ider $(\mathrm{F}$ & pair) & & NormFinder conditions \\
\hline $\begin{array}{l}\frac{\pi}{0} \\
\mathbb{0} \\
\end{array}$ & 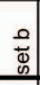 & 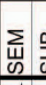 & & 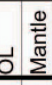 & $\begin{array}{l}\mathscr{0} \\
\end{array}$ & $\begin{array}{l}\mathscr{\infty} \\
\stackrel{\infty}{+} \\
\end{array}$ & 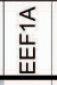 & $\overline{3}$ & 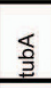 & $\begin{array}{c}\text { 害 } \\
\end{array}$ & 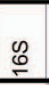 & $\begin{array}{l}\infty \\
\stackrel{\infty}{\mp} \\
\end{array}$ & $\underset{⿱ 亠 䒑}{\stackrel{4}{4}}$ & 흘 & 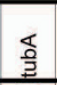 & $\begin{array}{l}\frac{9}{0} \\
\text { 苋 }\end{array}$ & 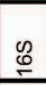 & $\stackrel{\mathscr{\infty}}{\mathscr{\infty}}$ & $\underset{⿱ 屮 凵}{\stackrel{5}{4}}$ & $\overline{3}$ & $\begin{array}{l}\text { 甾 } \\
\end{array}$ & $\begin{array}{l}\frac{9}{8} \\
\text { है } \\
\end{array}$ & $\stackrel{\mathscr{0}}{\stackrel{0}{0}}$ & $\stackrel{\mathscr{\infty}}{\underset{\sim}{2}}$ & \begin{tabular}{l}
\multirow{4}{\Psi}{} \\
\\
\end{tabular} & 믈 & $\begin{array}{l}\frac{6}{3} \\
3\end{array}$ & $\frac{\mathscr{m}}{\mathrm{U}}$ & \\
\hline$\sqrt{ }$ & & $\sqrt{ }$ & & & & & & V & & v & & & & & V & च & & & & V & & & & & & & & & \\
\hline$\sqrt{ }$ & & & $\sqrt{ }$ & & & & & $\nabla$ & & 甲 & & & & & च & 可 & & & & & & 甲 & & & & & & & \\
\hline$\checkmark$ & & & & $\checkmark$ & & & & 甲 & 曰 & & & & & & 甲 & च & & & & & च & & & & & & & & \\
\hline$\sqrt{ }$ & & 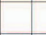 & & $\sqrt{ }$ & & & 甲 & $\nabla$ & & & & & & & $\square$ & 四 & & & & & $\nabla$ & & & & & & & & \\
\hline$\sqrt{ }$ & & $\sqrt{ }$ & $\sqrt{ } \mid$ & $\sqrt{ }$ & & & & 甲 & & 甲 & & & & & $\square$ & 可 & & & & & & 甲 & & & & & & & \\
\hline$\sqrt{ }$ & & $\sqrt{ }$ & $\sqrt{ }$ & $\sqrt{ } \sqrt{ }$ & & & & 可 & 曰 & & & & & $\square$ & 口 & & & & & च & & & & & & & & & \\
\hline & $\sqrt{ }$ & $\sqrt{ }$ & & & & & & $\nabla$ & 可 & & & & & $\nabla$ & & च & & & & & & 可 & & & & & & & \\
\hline & $\checkmark$ & & $\sqrt{ }$ & & & & 口 & & 口 & & & & & च & 甲 & & & & & & च & & & & & & & & \\
\hline & $\checkmark$ & & r & $\sqrt{ }$ & & & & च & 可 & & & & & $\nabla$ & 甲 & & & & & & च & & & & & & & & \\
\hline & $\checkmark$ & 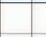 & & $\checkmark$ & & $\nabla$ & & $\nabla$ & & & & & & $\nabla$ & 甲 & & & & & च & & & & & & & & & \\
\hline & $\sqrt{ }$ & $\sqrt{ }$ & $\sqrt{ }$ & $\sqrt{ }$ & & & & च & 口 & & & & & च & 甲 & & & & & च & & & & & & & & & \\
\hline & $\sqrt{ }$ & $\sqrt{ }$ & $\sqrt{ }$ & $\sqrt{ } \sqrt{ }$ & & & & च & 可 & & & & & च & 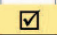 & & & & & च & & & & & & & & & \\
\hline$\sqrt{ }$ & $\sqrt{ }$ & $\sqrt{ }$ & & & & & & & $\nabla$ & $\nabla$ & & & & $\nabla$ & $\nabla$ & & & & & & 可 & & & & & & & & \\
\hline$\sqrt{ }$ & $\checkmark$ & & $\sqrt{ }$ & & & & 口 & & & 口 & & & & & 口 & 甲 & & & & & & 田 & & & & & & & \\
\hline$\sqrt{ }$ & $\sqrt{ }$ & & 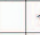 & $\sqrt{ }$ & & & & $\nabla$ & 田 & & & & & $\nabla$ & 甲 & & & & & & 口 & & & & & & & & \\
\hline$\sqrt{ }$ & $\checkmark$ & & & $\checkmark$ & & & & $\nabla$ & 田 & & & & 甲 & $\nabla$ & & & & & & 甲 & & & & & & & & & \\
\hline$\sqrt{ }$ & $\sqrt{ }$ & $\sqrt{ }$ & $\sqrt{ }$. & $\sqrt{ }$ & & & & & च & 甲 & & & & & 口 & च & & & & च & & & & & & & & & \\
\hline$\sqrt{ }$ & $\checkmark$ & $\sqrt{ }$ & $\sqrt{ }$ & $\sqrt{ } \sqrt{ }$ & & & & च & 可 & & & & & $\nabla$ & च & & & & & च & & & & & & & & & \\
\hline$\sqrt{ }$ & $\checkmark$ & $\sqrt{ }$ & $\sqrt{ }$ & $\sqrt{ } \sqrt{ }$ & & & & & & & & & & & & & & & & 甲 & & & & & & 四 & 口 & & (SEM,SUB,OL) vs M \\
\hline & & & & & $\begin{array}{l}\square \\
\square\end{array}$ & $\begin{array}{l}= \\
=\end{array}$ & $\begin{array}{l}\text { std de } \\
\text { Mvall }\end{array}$ & 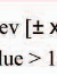 & $\begin{array}{l}x \text {-fold } \\
1.5\end{array}$ & & & च & $=1$ & best $r$ & referen & ce gen & e of $t$ & the pair & & & & & $=$ & not a & pplice & able & & & \\
\hline
\end{tabular}

Figure 2

Searching for the most stable candidate reference genes. Candidate reference genes for normalization were identified according to BestKeeper [18], geNorm [14] and NormFinder [19] procedures applied to the two set of samples (set a and set b) in O. vulgaris mantle (Mantle), supra-oesophageal mass (SEM), sub-oesophageal mass (SUB) and optic lobes (OL). In all tissues, stepwise exclusion was applied for those genes with expression variability above the required values for each algorithm. Values above the recommended thresholds are highlighted. $M$ value $(M)$ is the average pairwise variation of one selected reference gene compared to all the other control genes.

\section{Methods}

\section{Animals}

All the octopuses were collected from the wild and maintained in seawater until sacrifice. The animals were anesthetized in a sea water solution using $\mathrm{MgCl}_{2}$ [24]. A portion of the mantle (without the skin) and the brain was dissected out the animal. The brain was divided into its parts: supra-oesophageal mass (SEM), sub-oesophageal mass (SUB) and optic lobes (OL). Samples were transferred in plastic tubes ( $1 \mathrm{ml}$ of Eurozol, Euroclone), immediately frozen in liquid nitrogen, and stored at $80^{\circ} \mathrm{C}$ until further processed.

\section{Set $a$}

The octopuses (Octopus vulgaris, $\mathrm{N}=10$ ) were collected from different locations of the Bay of Napoli (Italy) throughout the year (2006). Their weight ranged from 30 to $2100 \mathrm{~g}$, spanning across a broad size/age range.

\section{Set $b$}

The octopuses $(O$. vulgaris, $\mathrm{N}=15)$ were caught in the Bay of Napoli in the same season (June - July, 2006); their size ranged between 200-550 g.

\section{RNA extraction and quantification}

Total RNA was extracted using Eurozol (Euroclone) according to the manufacturer's instructions. Contami- nating DNA was degraded by treating each sample with Turbo DNase Kit (Ambion) according to the instruction manual.

For all RNA samples, the absence of DNA contamination was tested by performing PCR with $\beta$-actin primers. The quantity and purity of total RNA extracted was estimated monitoring both the absorbance at $260 \mathrm{~nm}$ and ratios 260/280 nm and 260/230 nm by Nanodrop (ND-1000 UV-Vis Spectrophotometer; NanoDrop Technologies). The quality of RNA was evaluated by gel electrophoresis. Intact rRNA subunits (28S and $18 S$ ) were observed on the gel indicating minimal degradation of the RNA.

\section{cDNA synthesis}

For each sample, $2 \mu \mathrm{g}$ of total RNA extracted was retrotranscribed with SuperScript ${ }^{\mathrm{TM}}$ First-Strand Synthesis System for RT-PCR (Invitrogen) following the manufacturer's instructions. The cDNA was stored at $-20^{\circ} \mathrm{C}$ until further use. cDNA was diluted $1: 100$ with $\mathrm{H}_{2} \mathrm{O}$ prior to use in RTqPCR experiments, and 1:1500 when using 18S primers.

\section{Isolation of target and reference genes}

Target and reference genes were obtained from $O$. vulgaris using primers designed on conserved regions by means of bioinformatic analysis comparing homologous sequences 


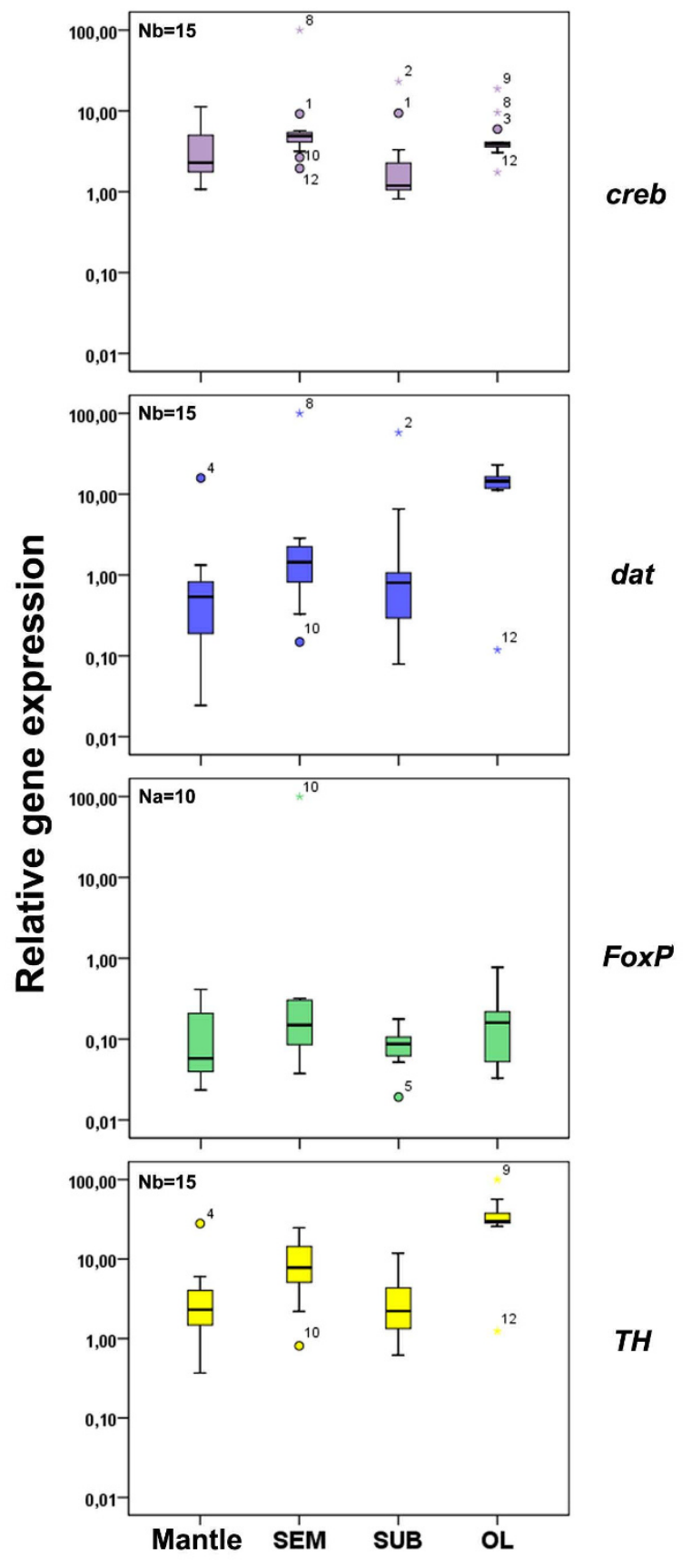

Figure 3

Relative target gene expression in different tissues for each data set. Relative expression distribution (box plots: for details see legend to Figure I) of creb, dat and $\mathrm{TH}$ (set b, $\mathrm{N}=15$ ) and FoxP (set a, $\mathrm{N}=10$ ) in 0 . vulgaris mantle, supra-oesophageal mass (SEM), sub-oesophageal mass (SUB) and optic lobes $(\mathrm{OL})$. $M$ value $(\mathrm{M})$ represents a measure of gene-stability and corresponds to the average pairwise variation of one selected reference gene compared to all the others. Relative gene expression ( $y$-axis) was calculated using tubA and $u b i$ as reference genes; see Methods for details. available in Gene Bank for the different taxa (see Additional file 1).

To isolate FoxP, retrotranscription reactions were performed using SuperScript ${ }^{\mathrm{TM}}$ One-Step RT-PCR Systems (Invitrogen) on total RNA extracted from the brain of adult octopuses using TRIZOL $^{\circledast}$ (Invitrogen) with inosinate degenerate primers (RPPfw 5'-AGACCGCCITTYACITAYGC-3' and AVWrev 5'-TCRTCIACVGTCCAIACIGC-3' for forward and reverse, respectively). Primers WKNfw 5'TGGAAGAATGCCGTGCGCCA CA-3' and WKNrev 5'TGTGGCGCACGGCATTCTTCCA-3' were used to obtain the $5^{\prime}$ and $3^{\prime}$ ends respectively using GeneRacer ${ }^{\mathrm{TM}}$ (Invitrogen) following the manifacturer's protocol. At the same time a PCR screening of cDNA libraries from octopus brain were performed to confirm the transcripts obtained (1111 bp).

For all cases (18S rRNA, ubi, dopamine transporter: dat, and tyrosine hydroxylase: $T H$ ) cDNAs were synthesized using SuperScript ${ }^{\mathrm{TM}}$ First-Strand Synthesis System for RTPCR (Invitrogen) from total RNA extracted from brains of adult octopuses using Eurozol (Invitrogen) according to the manufacturer's instructions. The cDNA obtained was used as template in PCR reactions to amplify genes of interest using primer pairs designed by Primer3 software [25].

For $18 S r R N A$, a 442 bp fragment was amplified with primers designed on the basis of Eledone cirrhosa $18 \mathrm{~S} r \mathrm{RNA}$ sequence (GeneBank accession number: AY557467): 18Sfw 5'-CGTTTTCCTCGATCAAGAGC-3' and 18Srev 5'CGAACTCGCGAAAGAAGAAG-3'.

For ubiquitin (ubi), a 324 bp cDNA sequence coding for ubi/ribosomal S27a protein was identified using the following primers: UBfw 5 '-TGTCAAGGCAAAGATTCAAGA3 ' and Ubrev 5'-GGCCATAAACACACCAGCTC-3'. These primers were designed on the basis of sequences present in Octopus eye EST library (http://cib.nig.ac.jp/dda/data base/octopus.htm, last visited: Aug, 2008).

For dopamine transporter (dat) we analyzed the ortholog sequence alignment of vertebrates and invertebrates. Degenerated oligonucleotides were designed to amplify conserved regions. A $506 \mathrm{bp}$ fragment coding for dat was amplified using the following primers: DATfor 15 '-TCKGGIAARGTDGTBTGGTT-3' and DATrev3 5'-ATIGCYCIGADCCNCCRAA-3'.

For tyrosine hydroxylase $(T H)$, the most conserved regions of vertebrate and invertebrate ortholog sequences were identified and degenerated oligos were designed for PCR reactions. The primers Thfor1 5'-RTSTTYCAGWSYACICAGTA-3' and Threv2 5'-AAYTCVACRGTGAACCAGTA-3' were used to amplify a fragment of $539 \mathrm{bp}$. 
cDNA amplified fragments were purified from gel agarose using QIAquick ${ }^{\circledR}$ Gel extraction kit (Qiagen) and cloned into pCRII-TOPO vector (Invitrogen) according to the instruction manual. The resulting plasmids were sequenced using M13 reverse primer and T7. Sequences of the PCR products obtained were analyzed by BLASTX and BLASTP programs.

The c-AMP response element binding protein (creb) cDNA sequence was found after screening $O$. vulgaris cDNA library constructed from mRNA of the supra-oesophageal mass. The cDNA sequence coding for Aplysia creb1 $\alpha$ was used to screen the library (gift from Dr E.R. Kandel Laboratory). The sequence identified was 4313 bp long and coded for a protein of 296 amminoacids.

The resulting alignments of $O$. vulgaris translated sequences with invertebrate and vertebrate orthologues are summarized in Additional file 1.

\section{Primer design for RT-qPCR}

All RT-qPCR primers were designed by Primer 3 software [25]. Table 1 lists the primers' sequences together with amplicon size. Target genes' sequences amplified by the primer pairs were evaluated with MFOLD software [26] in order to check for secondary structures at the site of primer binding. Specificity of PCR products was checked by melting curve analysis followed by gel electrophoresis and DNA sequencing.

\section{Real Time PCR}

The efficiency of each primer pair (Table 1) was calculated according to standard methods curves using the equation $\mathrm{E}=10^{-1 / \text { slope }}$. Five serial dilutions were set up to determine Ct values and reaction efficiencies for all primer pairs. Standard curves were generated for each oligonucleotide pairs using the Ct value versus the logarithm of each dilution factor.

Diluted cDNA was used as template in a reaction containing a final concentration of $0.3 \mu \mathrm{M}$ for each primer and $1 \times$ FastStart SYBR Green master mix (total volume of $25 \mu \mathrm{l}$ ). PCR amplifications were performed in a Chromo ${ }^{\mathrm{TM}}$ RealTime Detector (Biorad) thermal cycler using the following thermal profile: $95^{\circ} \mathrm{C}$ for $10 \mathrm{~min}$, one cycle for cDNA denaturation; $95^{\circ} \mathrm{C}$ for $15 \mathrm{sec}$ and $60^{\circ} \mathrm{C}$ for $1 \mathrm{~min}, 40$ cycles for amplification; $72^{\circ} \mathrm{C}$ for $5 \mathrm{~min}$, one cycle for final elongation; one cycle for melting curve analysis (from $60^{\circ} \mathrm{C}$ to $95^{\circ} \mathrm{C}$ ) to verify the presence of a single product. Each assay included a no-template control for each primer pair. To capture intra-assay variability all RTqPCR reactions were carried out in triplicate (set a) or duplicate (set b). Fluorescence was measured using Opticon Monitor 3.1 (Biorad).

\section{Stability analysis of reference genes}

The distribution of the Ct was first calculated for each tissue considering all the samples and reported as box plot. The Ct values were obtained from the average of each animal tissue.

Three different gene normalization algorithms were utilized in this work: BestKeeper [18], geNorm [14] and NormFinder [17]. For each one a step-wise exclusion method have been applied in order to identify the best candidate reference genes.

\section{Expression analysis of target genes}

The expression of each target gene (relative to the most stable reference genes [11]) was calculated applying the following formula:

relative gene expression $=\frac{\left(E u b i i^{C t u b i} \cdot E t u b C t t u b A\right.}{{ }^{1 / 2}}$ were:

ubi: ubi

tubA: tubulin

trg: target gene

\section{Data analysis}

Raw Ct data were exported to a worksheet for further analysis. SPSS 16 was used for statistical analysis (One-way ANOVA followed Dunnett post-hoc test). Significance level was set at 5\%.

\section{Authors' contributions}

OS and IZ participated in the design of the study, performed all the experiments and drafted the manuscript. FR and MB carried out data analysis and helped to draft the manuscript. MB participated in the design of the study and assisted in RT-qPCR experiments design and realization. MIA and EB participated in the design and coordination of the study and helped to draft the manuscript. GF conceived and supervised the study. All authors read and approved the final manuscript.

\section{Additional material}

\section{Additional file 1}

The alignment of $\mathrm{O}$. vulgaris translated sequences with their invertebrate and vertebrate orthologous. For each gene alignment, identity matrix and cDNA sequence are provided.

Click here for file

[http://www.biomedcentral.com/content/supplementary/14712199-10-70-S1.pdf] 


\section{Acknowledgements}

We are indebted to Drs M. Branno and A. Arcucci who greatly contributed to creb identification and isolation in 0 . vulgaris. We are grateful to Luciana Borrelli for critical reading of the manuscript and suggestions. This work was funded by Istituto Banco di Napoli, Fondazione (Italy) and the network of Excellence "Marine Genomics Europe" (GOCE-04-505403).

\section{References}

I. Huggett J, Dheda K, Bustin S, Zumla A: Real-time RT-PCR normalisation; strategies and considerations. Genes Immun 2005, 6:279-284.

2. Radonic A, Thulke S, Mackay IM, Landt O, Siegert W, Nitsche A: Guideline to reference gene selection for quantitative realtime PCR. Biochem Biophys Res Commun 2004, 3 I 3:856-862.

3. Skern R, Frost $P$, Nilsen F: Relative transcript quantification by quantitative PCR: roughly right or precisely wrong? $B M C \mathrm{Mol}$ Biol. 2005 Apr 26;6(I): 10. 2005, 6(1):10.

4. Thellin O, Zorzi W, Lakaye B, De Borman B, Coumans B, Hennen G, Grisar T, Igout A, Heinen E: Housekeeping genes as internal standards: use and limits. J Biotechnol 1999, 75:291-295.

5. Dheda K, Huggett JF, Bustin SA, Johnson MA, Rook G, Zumla A: Validation of housekeeping genes for normalizing RNA expression in real-time PCR. Biotechniques 2004, 37: I I2-I |4.

6. Dheda K, Huggett JF, Chang JS, Kim LU, Bustin SA, Johnson MA, Rook $G A$, Zumla $A$ : The implications of using an inappropriate reference gene for real-time reverse transcription PCR data normalization. Anal Biochem 2005, 344:|4|-|43.

7. Jain M, Nijhawan A, Tyagi AK, Khurana JP: Validation of housekeeping genes as internal control for studying gene expression in rice by quantitative real-time PCR. Biochem Biophys Res Commun 2006, 345:646-65I.

8. Liu DW, Chen ST, Liu HP: Choice of endogenous control for gene expression in nonsmall cell lung cancer. Eur Respir J 2005, 26: $1002-1008$.

9. Mamo S, Gal AB, Bodo S, Dinnyes A: Quantitative evaluation and selection of reference genes in mouse oocytes and embryos cultured in vivo and in vitro. $B M C \operatorname{Dev} B i o l$ 2007, 7:14.

10. Schmittgen TD, Zakrajsek BA: Effect of experimental treatment on housekeeping gene expression: validation by real-time, quantitative RT-PCR. J Biochem Biophys Methods 2000, 46:69-8I.

II. Pfaffl MW, Horgan GW, Dempfle L: Relative expression software tool (REST) for group-wise comparison and statistical analysis of relative expression results in real-time PCR. Nucleic Acids Res 2002, 30(9):e36.

12. Vandesompele J, De Preter K, Pattyn F, Poppe B, Van Roy N, De Paepe A, Speleman F: Accurate normalization of real-time quantitative RT-PCR data by geometric averaging of multiple internal control genes. Genome Biol 2002, 3(7):research0034.

13. Borrelli L, Fiorito G: Behavioral Analysis of Learning and Memory in Cephalopods. Learning Theory and Behavior. Vol. I (Menzel, R., Volume Editor) of Learning and Memory: A Comprehensive Reference, 4 vols. (Byrne, J., Editor) 2008:605-628.

14. Hochner B, Shomrat T, Fiorito G: The octopus: a model for a comparative analysis of the evolution of learning and memory mechanisms. Biol Bull 2006, $210: 308-317$.

15. Young JZ: The Anatomy of the Central Nervous System of Octopus vulgaris. Claredon Press, Oxford; 1971.

16. Pfaffl MW, Tichopad A, Prgomet C, Neuvians TP: Determination of stable housekeeping genes, differentially regulated target genes and sample integrity: BestKeeper - Excel-based tool using pair-wise correlations. Biotechnology Letters 2004, 26:509-5I5.

17. Andersen CL, Jensen JL, Orntoft TF: Normalization of real-time quantitative reverse transcription-PCR data: a model-based variance estimation approach to identify genes suited for normalization, applied to bladder and colon cancer data sets. Cancer Res 2004, 64:5245-5250.

18. Fernandes JM, Mommens M, Hagen O, Babiak I, Solberg C: Selection of suitable reference genes for real-time PCR studies of Atlantic halibut development. Comp Biochem Physiol B Biochem Mol Biol 2008, I 50:23-32.

19. Olsvik PA, Lie KK, Jordal AEO, Nilsen TO, Hordvik I: Evaluation of potential reference genes in real-time $R T-P C R$ studies of Atlantic salmon. BMC Mol Biol. 2005 Nov 17;6:2I 2005, 6:2I.
20. Zhong Q, Zhang Q, Wang Z, Qi J, Chen Y, Li S, Sun Y, Li C, Lan X: Expression profiling and validatio of potential reference genes during Paralichthylus olivaceus embryogenesis. Mar Biotechnol (NY) 2008, I 0(3):310-8.

21. Toegel S, Huang WW, Piana C, Unger FM, Wirth M, Goldring MB, Gabor F, Viernstein H: Selection of reliable reference genes for qPCR studies on chondroprotective action. BMC Mol Biol 2007, 8:I3.

22. Hibbeler S, Scharsack JP, Becker S: Housekeeping genes for quantitative expression studies in the three-spined stickleback Gasterosteus aculeatus. BMC Mol Biol 2008, 9:18.

23. Messenger JB: Neurotransmitters of cephalopods. Invertebrate Neuroscience 1996, 2:95-II4.

24. Messenger JB, Nixon M, Ryan KP: Magnesium chloride as an anaesthetic for cephalopods. Comp Biochem Physiol C Comp Pharmacol 1985, 82:203-205.

25. Rozen S, Skaletsky HJ: Primer3 on the WWW for general users and for biologist programmers. In Bioinformatics Methods and Protocols: Methods in Molecular Biology Edited by: Krawetz S, Misener S. Totowa, NJ: Humana Press; 2000:365-386.

26. Zuker M: Mfold web server for nucleic acid folding and hybridization prediction. Nucl Acids Res 2003, 31:3406-34I 5.
Publish with Bio Med Central and every scientist can read your work free of charge

"BioMed Central will be the most significant development for disseminating the results of biomedical research in our lifetime. "

Sir Paul Nurse, Cancer Research UK

Your research papers will be:

- available free of charge to the entire biomedical community

- peer reviewed and published immediately upon acceptance

- cited in PubMed and archived on PubMed Central

- yours - you keep the copyright

Submit your manuscript here:

http://www.biomedcentral.com/info/publishing_adv.asp
BioMedcentral 